\title{
Evolving Concepts in The Rotator Cuff Footprint
}

\author{
Ajinkya Achalare ${ }^{1}$, Nilesh Kamat ${ }^{2}$, M.P. Ramraju Mudunuri ${ }^{1}$
}

\section{Abstract}

Rotator cuff (RC) tears are a common presentation in day-to-day clinical settings. Majority of the symptomatic patients are treated by a surgical repair. Before considering a surgical intervention, it is vital to understand the anatomy of RC footprint and restore it, in order to achieve an optimal tension-free repair, better healing and subsequently good clinical outcomes. Concepts pertaining to the RC footprint over the greater tuberosity (GT) have been constantly changing in the past two decades with meticulous anatomical studies. Traditional concepts of individual insertions of supraspinatus (SSP) and infraspinatus (ISP), SSP alone playing the vital role in shoulder abduction, now stand obsolete. Similarly, being the largest muscle-tendon unit, subscapularis (SSC) has been studied extensively and is now known to have a three dimensional insertion over lesser tuberosity. This article reviews the evolution of concepts pertaining to RC insertion and their clinical application.

Keywords: Rotator cuff; Footprint; Three-dimensional insertion.

\section{Introduction}

Rotator cuff (RC) comprises of a group of four important muscles required for normal functioning of the shoulder joint. $\mathrm{RC}$ tears in an active population are a common presentation in day-to-day clinical setting. Surgical repair of these tears in symptomatic patients remains the ideal treatment in their management. Thorough understanding of the footprint of each component of the $\mathrm{RC}$ is critical and a prerequisite before approaching the surgical intervention. It enables the surgeon to achieve an optimal repair and restore the native anatomy of rotator cuff. Understanding the RC anatomy, especially the footprint, has gone through a process of evolution. Traditionally, anatomy textbooks have described the supraspinatus (SSP) and infraspinatus (ISP) tendons to have their individual insertions over the GT, with SSP being the most vital structure for abduction of the shoulder [1, 2]. However, meticulous cadaveric studies in the past two decades have modified these concepts to great extent. This article aims to review the process of evolution of concepts in the anatomy of RC footprint.

\section{Supraspinatus and Infraspinatus}

\section{Layers of Rotator Cuff Tendon}

Clark and Harryman were first ones to describe the macroscopic as well as microscopic anatomy of the $\mathrm{RC}$ in detail [3]. RC tendon was described to be formed by five layers; layer 1 : fibers of coracohumeral ligament, layer 2: densely packed fibers in parallel orientation, layer 3: randomly oriented smaller fibers, layer 4: loose connective tissue and layer 5: articular capsule (Figure 1), with average thickness of the tendon ranging between 9 to $12 \mathrm{~mm}$ [3]. The concept of SSP and ISP tendons interdigitating to form a single unit near the insertion was put forth.

\section{Insertion in Reference to The Facets}

In-depth analysis of cuff insertion with respect to the facets of GT by Minagawa et al revealed SSP to have its insertion over the entire length of superior facet and superior half of middle facet, whereas ISP was seen getting inserted over the middle facet, overlapping the posterior half of SSP tendon from bursal side4. Insertions were described with respect to two bony landmarks, namely the anterior margin of GT and the sulcus (superior aspect of anatomical neck) over the humeral head. Anterior $12.6 \mathrm{~mm}(+/-1.1)$ of tendon from anterior margin of GT consisted only of SSP, middle $9.8 \mathrm{~mm}(+/-3.2)$ consisted of both SSP \& ISP and the posterior most $12.9 \mathrm{~mm}(+/-3.2)$ part was formed solely by ISP [4]. Although the sulcus was conventionally thought to be a landmark for the SSP-ISP junction [5], the anterior margin of SSP actually lied 4.3 $\mathrm{mm}(+/-2.4)$ anterior to the sulcus [4]. All this information helped to understand the cuff tear morphology better, but intra-operative difficulty to differentiate between SSP and ISP tears persisted

\section{Concept of 'footprint'}

Peculiar pattern of RC insertion over GT gave rise to the term 'footprint' by Tierney et al [6]. Further footprint analysis by Curtis et al revealed SSP insertion to be of trapezoidal shape with wider proximal and narrow distal attachment from 11 to 1 O'clock [7]. ISP was the second largest unit after subscapularis (SSC), inserted from 1 to 3 O'clock, after wrapping around the posterior aspect of SSP insertion (Figure 2). Area between the articular cartilage and inferior insertion was termed as 'bare area'. Under Scanning Electron Microscopy (SEM), SSP tendon was found to be densely adherent to the articular capsule with all the layers arranged in parallel fashion and the insertion

\footnotetext{
${ }^{1}$ Kamat Clinic, Pune, Maharashtra, India.

${ }^{2}$ Department of Shoulder Surgery, Sancheti Institute of Orthopaedics and

Rehabilitation, Pune, Maharashtra, India.

Address of Correspondence:

Dr. Ajinkya Achalare,

Clinical Fellow in Arthroscopy, Kamat Clinic,

Pune, Maharashtra, India.

E-mail: ajinkya1401@gmail.com

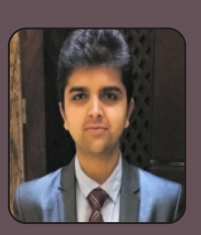

Dr. Ajinkya Achalare

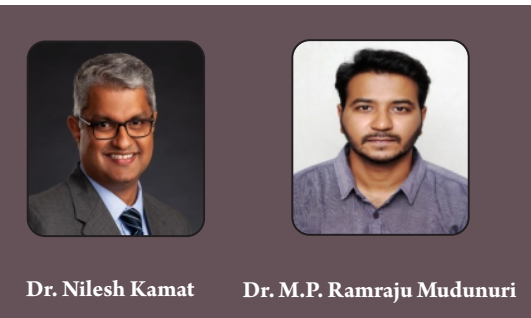

Dr. Nilesh Kamat $\quad$ Dr. M.P. Ramraju Mudunuri

Submitted: 10 March 2021; Reviewed: 20 April 2021; Accepted: 18 May 2021; Published: 10 June 2021

Asian Journal of Arthroscopy | ISSN 2456-1169| Available on www.asianarthroscopy.com | DOI:10.13107/aja.2021.v06i01.019|

This is an open access journal, and articles are distributed under the terms of the Creative Commons Attribution Non-Commercial-Share Alike 4.0 License (http://creativecommons.org/licenses/by-nc-sa/4.0) which allows others to remix, tweak, and build upon the work non-commercially as long as appropriate credit is given and the new creation are licensed under the identical terms.
} 


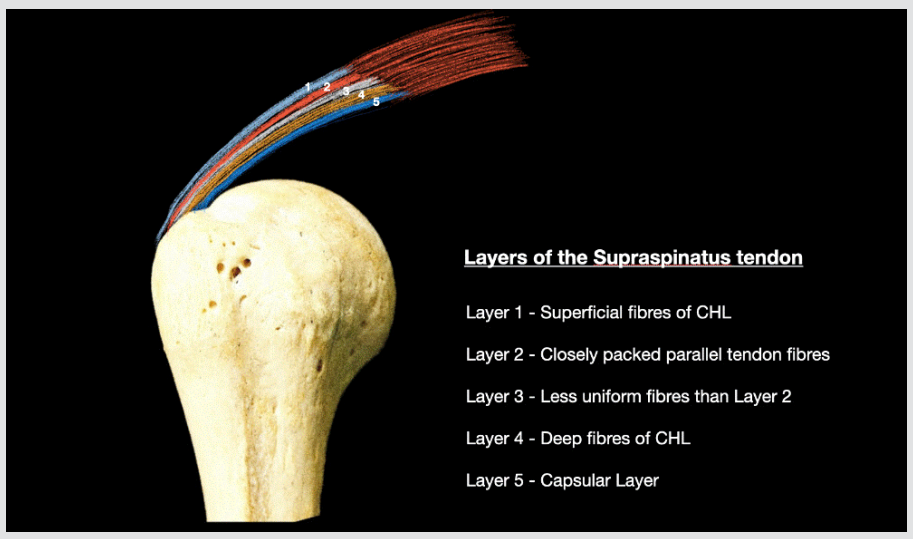

Figure 1: Five layers of supraspinatus tendon as observed in oblique coronal section

extending up to the lip of the GT [7].

Ellman utilized the footprint concept for quantifying the 'area of defect' and devising a classification system for rotator cuff tears (RCT) [8]. Likewise, Ruotolo defined a method to quantify articular surface partial thickness tears by calculating the amount of footprint exposed along the width of footprint in medio-lateral plane [9].

\section{Increasing Importance of Infraspinatus}

Conventional concept of SSP being the most commonly involved RC component in RCTs was challenged by Mochizuki et al, as a significant number of these patients demonstrated associated ISP atrophy [10]. SSP insertion was described over the anteromedial aspect of the highest impression of GT forming a really small right angled triangle with its base along the articular surface, tapering distally with the average lateral margin width of only $1.3 \mathrm{~mm}$. In $21 \%$ specimens, SSP insertion extended up to the lesser tuberosity (LT) forming the roof of bicipital groove [10]. ISP insertion is a large trapezoid with a narrow medial and wider lateral margin. It involves almost half of the highest impression, reaching up to its anterior margin [10] (Figure 3). These findings support the newer concept of higher contribution of ISP to the shoulder abduction than previously thought. Table 1 summarizes the footprint dimensions described by various authors.

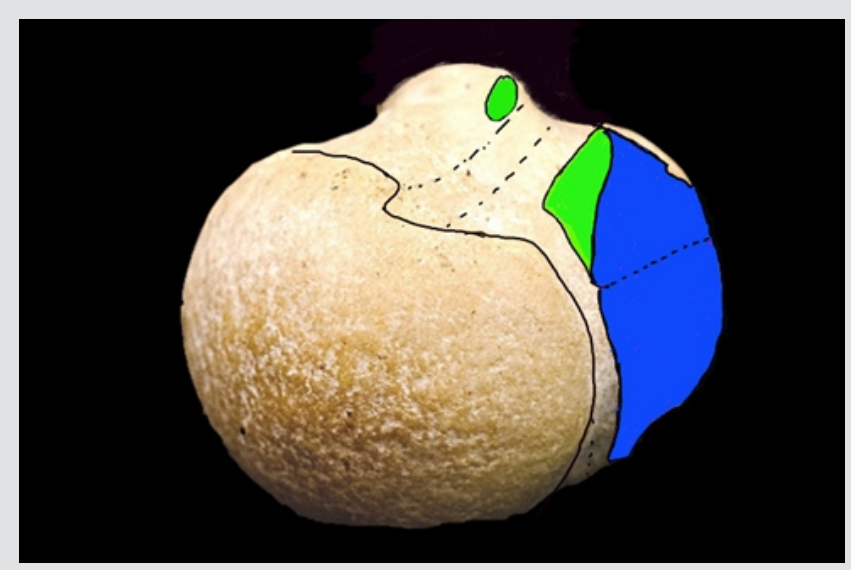

Figure 3: Newer concept of footprint anatomy - small triangular insertion of SSP (green) over anteromedial aspect of superior facet with a slip of attachment over lesser tuberosity. Large trapezoidal insertion of ISP (blue) over superior and middle facets

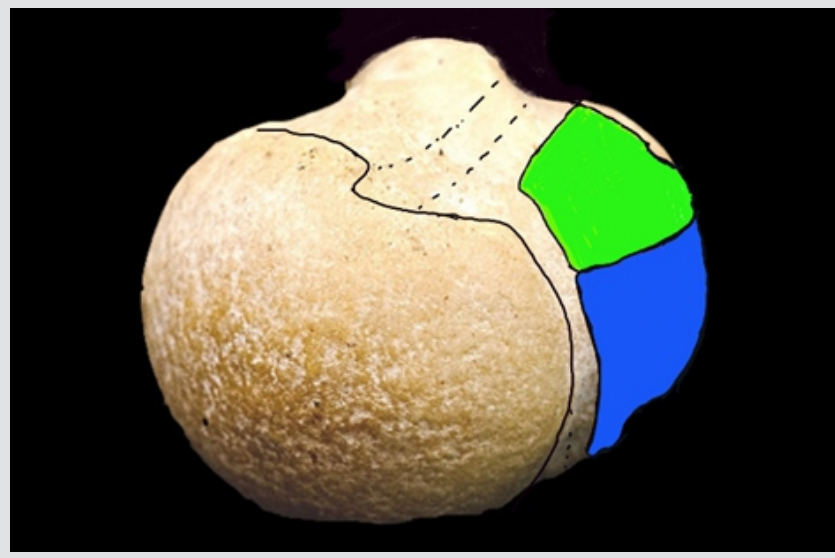

Figure 2: Older concept of footprint anatomy - SSP attachment (green) over superior facet and ISP insertion (blue) over middle facet of greater tuberosity

\section{Teres Minor}

Despite of being the smallest muscle tendon unit, teres minor (TM) has a comparatively larger insertion over the inferior facet. It gets inserted in a triangular shape from 3 to 5 O'clock at around $10 \mathrm{~mm}$ from the articular cartilage (Figure 4). Footprint dimensions include average maximum length of $29 \mathrm{~mm}$ and width of $21 \mathrm{~mm}$ [7].

However, the newer concept by Hamada et al suggests TM to be formed by two separate muscle bundles. At the insertion site, the upper bundle has a round tendinous attachment over inferior facet of GT, whereas the lower bundle has a linear muscular attachment over the posterior aspect of the surgical neck of humerus [11].

\section{Subscapularis}

The importance of subscapularis (SSC) has always been underplayed until the recent past when Burkhart and co-workers emphasized the clinical significance of SSC tears [12]. SSC is the largest muscle tendon unit with the insertion of all the RC muscles. Curtis et al have described the insertion on the LT in two-dimensional plane as a 'comma shaped' insertion [7] (Figure 5). Burkhart and co-workers have described the shape as trapezoidal similar to the geographic map of state of Nevada [12]. However, it was J C Yoo et al, who described the threedimensional insertion pattern and the facet concept for insertion of

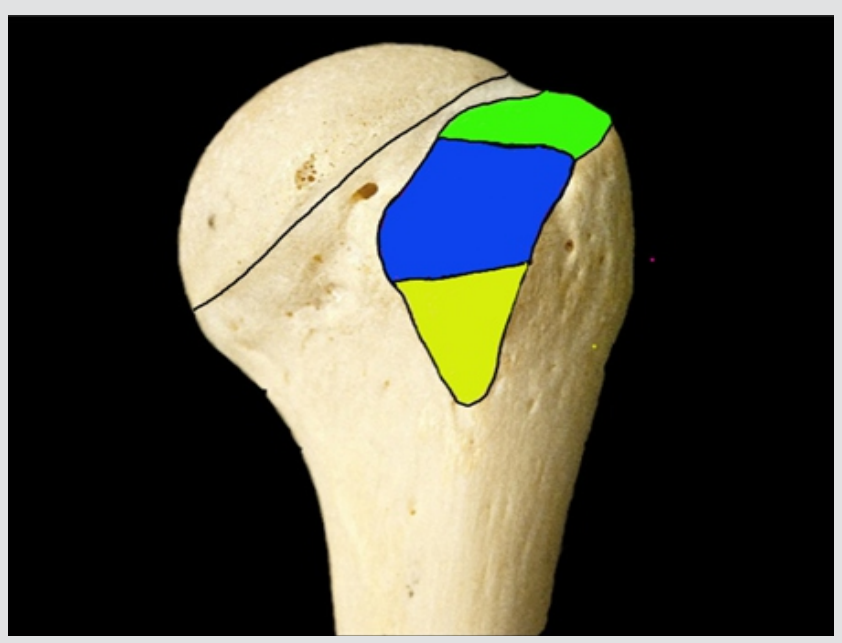

Figure 4: Triangular insertion of teres minor (yellow) over inferior facet 


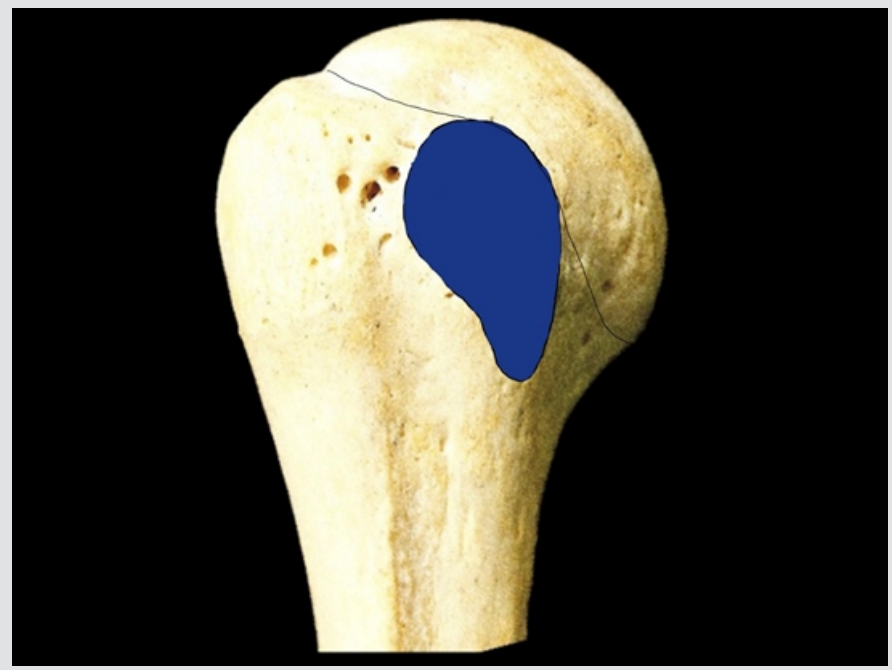

Figure 5: Older concept of 'comma shaped' insertion of subscapularis (blue) over lesser tuberosity

\section{SSC in 2015 [13].}

It is a well-documented fact that the thickness of SSC muscle varies in superior to inferior direction $[12,13]$. In the upper portion, the maximum width of the insertion is 16 to $18 \mathrm{~mm}$. Also, the upper part of the insertion is purely tendinous. As we move from superior to inferior direction, the insertion narrows down and in the lower half it is purely muscular. The total length of the insertion was described as $34.9 \mathrm{~mm}$ however the tendinous portion was only $26.3 \mathrm{~mm}$ [13]. This is of clinical relevance while performing arthroscopic repair as it is possible only to restore the tendinous portion of the insertion.

Previous authors have described a bare area which is the area between the articular cartilage and the actual insertion. Ide et al and Curtis et al described this measurement as $0 \mathrm{~mm}$ at the superior most portion of the insertion and up to $18 \mathrm{~mm}$ at the distal most portion of the medial edge of the insertion $[7,14]$.

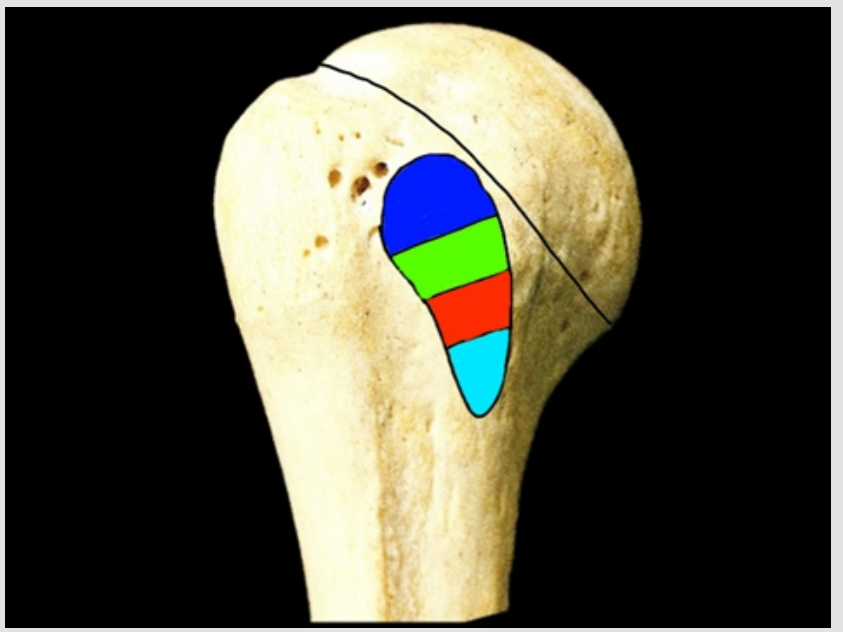

Figure 6: Newer concept of three-dimensional insertion of subscapularis over four facets of lesser tuberosity: Facet 1 (blue), facet 2 (green), facet 3 (red) and facet 4 (blue)

JC Yoo and co-workers described the facet concept of SSC insertion, wherein the insertion was compartmentalized into 4 facets based on the imaging and digitalization findings on a cadaveric study [15] (Figure $6)$. The superior most facet is the main tendinous insertion and represents almost $1 / 3^{\text {rd }}$ area of the total insertion. The first 2 facets are inserted with the tendinous portion and represent $60 \%$ of the total insertion. Attachments to rest of the two facets are purely muscular. The mean measurements of subscapularis insertion are summarized in Table 2 .

\section{Discussion}

The anatomy of the RC has not changed over the years. However, better imaging and evolution of medical facilities has helped us understand the anatomy of the RC in a better way. Also, this knowledge can be applied in the clinical setting while treating RCTs and proximal

Table 1: Review of footprint dimensions over greater tuberosity

\begin{tabular}{|c|c|c|c|c|c|c|c|c|}
\hline \multirow{3}{*}{ Author } & \multicolumn{4}{|c|}{ Supraspinatus } & \multicolumn{4}{|c|}{ Infraspinatus } \\
\hline & \multicolumn{2}{|c|}{$\begin{array}{c}\text { Anteroposterior } \\
\text { Width }\end{array}$} & \multirow[b]{2}{*}{$\begin{array}{l}\text { Medio-lateral } \\
\text { Length } \\
\text { (mm) }\end{array}$} & \multirow[b]{2}{*}{$\begin{array}{l}\text { Area } \\
\left(\mathrm{cm}^{2}\right)\end{array}$} & \multicolumn{2}{|c|}{$\begin{array}{c}\text { Anteroposterior } \\
\text { Width }\end{array}$} & \multirow[b]{2}{*}{$\begin{array}{l}\text { Medio-lateral } \\
\text { Length } \\
(\mathrm{mm})\end{array}$} & \multirow[b]{2}{*}{$\begin{array}{l}\text { Area } \\
\left(\mathrm{cm}^{2}\right)\end{array}$} \\
\hline & $\begin{array}{c}\text { Medial } \\
\text { margin } \\
(\mathrm{mm})\end{array}$ & $\begin{array}{c}\text { Lateral } \\
\text { margin } \\
(\mathrm{mm})\end{array}$ & & & $\begin{array}{c}\text { Medial } \\
\text { margin } \\
(\mathrm{mm})\end{array}$ & $\begin{array}{c}\text { Lateral } \\
\text { margin } \\
(\mathrm{mm})\end{array}$ & & \\
\hline Dugas [15] & - & 16.3 & 12.7 & 1.55 & - & 16.4 & 13.4 & 1.76 \\
\hline Ruotolo [9] & - & 25 & 12.1 & - & - & - & - & - \\
\hline Curtis [7] & - & 23 & 16 & - & - & 29 & 19 & - \\
\hline Mochizuki [10] & 12.9 & 1.3 & 6.9 & - & 20.2 & 32.7 & 10.2 & - \\
\hline
\end{tabular}

Table 2: Dimensions of subscapularis insertion over lesser tuberosity

\begin{tabular}{|c|c|}
\hline Dimension & Measurements (mm) \\
\hline Superior to inferior length (Tendinous part) & $15-30$ \\
\hline Medial to lateral width (Superior portion) & $15-26$ \\
\hline Medial to lateral width (Inferior portion) & $01-07$ \\
\hline
\end{tabular}


humerus fractures. Understanding the footprint of the $\mathrm{RC}$ allows the surgeon to correlate it with the tear patterns. As the ISP winds around the GT, it is important to understand the retraction pattern which aids in achieving a desirable low-tension repair. The layered concept of SSP helps in understanding the delaminated tear patterns and the importance of incorporating all the layers in the repair to provide adequate strength to the repair. SSP and ISP tendons blend together close to their insertion and while repairing these tendons; it is not always possible to repair them as separate units. Also, with various studies it has been documented that ISP has a significantly larger area of attachment on the GT as compared to SSP. This should be kept in mind while addressing the RCTs and planning their repair.

Various investigators have found that SSC tears affect predominantly the upper tendinous portion in a majority of cases. Even according to the facet concept, tears involving the upper two facets involve mainly the tendinous attachment [13]. Arthroscopically, only the tendinous portion of the subscapularis is visualized and this knowledge is useful while repairing subscapularis tears. Also, in up to 30 $\%$ cases of SSC tear, there is an associated partial SSP tear affecting the anterior most portion $[12,13]$, validating the concept of an additional slip of SSP insertion over the superior aspect of LT.
Conclusion

In-depth analysis of RC anatomy, especially the footprint, has helped surgeons to quantify and classify RCTs and plan their management accordingly. Restoration of the RC footprint, inclusion of the deeper lamina of RC in the repair and repair of superior tendinous portion of SSC increase the prospects of achieving better clinical outcomes.

\section{References}

1. Clemente CD, editor. Gray's anatomy of the human body. 30th ed. Philadelphia: Lea \& Febiger; 1985. Osteology, and muscles and fasciae of the upperlimb.p233-4.

2. Johnson D, Ellis $H$, editors. Pectoral girdle, shoulder region, and axilla. In: Standring S, Ellis H, Healy JC, Johnson D, Williams A, Collins P, Wigley C, editors. Gray's anatomy: the anatomical basis of clinical practice. 39th ed. Edinburgh:Elsevier Churchill Livingstone; 2005. p17-49.

3. Clark JM, Harryman DT II. Tendons, ligaments, and capsule of the rotator cuff: Gross and microscopic anatomy. J Bone Joint Surg Am 1992;74:713725 .

4. Minagawa H, Itoi E, Konno N, et al. Humeral attachment of the supraspinatus and infraspinatus tendons: An anatomic study. Arthroscopy 1998;14:302306.

5. Ellman H, Gartsman GM, Hengst TC. Arthroscopic shoulder surgery and related procedures. Philadelphia: Lea \& Febiger, 1993.

6. Tierney JJ, Curtis AS, Kowalik DL, Scheller AD. The footprint of the rotator cuff.Arthroscopy 1999; 15:556-557.

7. Curtis AS, Burbank KM, Tierney JJ, Scheller AD, Curran AR. The insertional footprint of the rotator cuff: an anatomic study. Arthroscopy. 2006 Jun;22(6):609.e1. doi: 10.1016/j.arthro.2006.04.001. PMID: 16762697.

8. Ellman H. Diagnosis and treatment of incomplete rotator cuff tears. Clin Orthop 1990;254:64-74.

9. Ruotolo C, Fow JE, Nottage WM. The supraspinatus footprint: An anatomic study of the supraspinatus insertion. Arthroscopy 2004;20:246-249.
10. Mochizuki T, Sugaya H, Uomizu M, Maeda K, Matsuki K, Sekiya I, Muneta T, Akita K. Humeral insertion of the supraspinatus and infraspinatus. New anatomical findings regarding the footprint of the rotator cuff. J Bone Joint Surg Am. 2008 May;90(5):962-9. doi: 10.2106/JBJS.G.00427. PMID: 18451386.

11. Hamada J, Nimura A, Yoshizaki K, Akita K. Anatomic study and electromyographic analysis of the teres minor muscle. J Shoulder Elbow Surg. 2017 May;26(5):870-877. doi: 10.1016/j.jse.2016.09.046. Epub 2017 Jan 10.PMID: 28087164.

12. Richards DP, Burkhart SS, Tehrany AM, Wirth MA. The subscapularis footprint: an anatomic description of its insertion site. Arthroscopy. 2007 Mar;23(3):251-4. doi: 10.1016/j.arthro.2006.11.023. PMID: 17349466.

13. Yoo JC, Rhee YG, Shin SJ, Park YB, McGarry MH, Jun BJ, Lee TQ. Subscapularis tendon tear classification based on 3-dimensional anatomic footprint: a cadaveric and prospective clinical observational study. Arthroscopy. 2015 Jan;31(1):19-28. doi: 10.1016/j.arthro.2014.08.015. Epub2014 Oct 18. PMID: 25442662.

14. Ide J, Tokiyoshi A, Hirose J, Mizuta H. An anatomic study of the subscapularis insertion to the humerus: the subscapularis footprint. Arthroscopy. 2008 Jul;24(7):749-53. doi: 10.1016/j.arthro.2008.02.009. Epub2008 Apr 14.PMID: 18589262.

15. Dugas JR, Campbell DA, Warren RF, Robie BH, Millett PJ. Anatomy and dimensions of rotator cuff insertions. J Shoulder Elbow Surg 2002; 11:498503. doi:10.1067/mse.2002.126208.

Declaration of patient consent: The authors certify that they have obtained all appropriate patient consent forms. In the form, the patient has given his consent for his images and other clinical information to be reported in the Journal. The patient understands that his name and initials will not be published, and due efforts will be made to conceal his identity, but anonymity cannot be guaranteed.

Conflict of interest: Nil Source of support: None

\section{How to Cite this Article}

Achalare A, Kamat N, Mudunuri MPR | Evolving Concepts in The Rotator Cuff Footprint | Asian Journal of Arthroscopy | January-June 2021;6(1):11-14. 